RUNNING HEAD: MVPA and distress latent changes

\title{
Longitudinal Relations Between Psychological Distress and Moderate-to-Vigorous \\ Physical Activity: A Latent Change Score Approach
}

*Daniel F. Gucciardi ${ }^{1,2}$, Kwok Hong Law ${ }^{3}$, Michelle D. Guerrero ${ }^{4}$, Eleanor Quested ${ }^{2,5}$, Cecilie Thøgersen-Ntoumani ${ }^{2,5}$, Nikos Ntoumanis ${ }^{2,5}$, and Ben Jackson ${ }^{3}$

${ }^{1}$ School of Physiotherapy and Exercise Science, Curtin University; ${ }^{2}$ Physical Activity and Well-Being Lab, Curtin University; ${ }^{3}$ School of Human Sciences (Exercise and Sports Science), The University of Western Australia $;{ }^{4}$ Department of Kinesiology, University of Windsor; ${ }^{5}$ School of Psychology, Curtin University

*Address correspondence to Daniel Gucciardi, School of Physiotherapy and Exercise Science, Curtin University, GPO Box U1987, Western Australia, 6845. Phone: +61 89266 3653. Email: daniel.f.gucciardi@gmail.com.

Funding: Daniel Gucciardi is supported by a Curtin Research Fellowship. Michelle Guerrero was supported by a Social Sciences and Humanities Research Council of Canada Michael Smith Foreign Study Supplement Award.

Acknowledgements. This paper uses unit record data from Growing Up in Australia, the Longitudinal Study of Australian Children (LSAC) Survey. The study is conducted in partnership between the Department of Social Services (DSS), the Australian Institute of Family Studies (AIFS) and the Australian Bureau of Statistics (ABS). The views expressed in this report are those of the authors alone and do not represent those of DSS, AIFS, the ABS or DEEWR.

Accepted for publication in Psychology of Sport and Exercise on $12^{\text {th }}$ February 2019 


\section{Abstract}

2 Objectives: The effect of physical inactivity on mental health risk is well established;

3 however, less is known about about how psychological distress might deter participation in

4 physical activity. Guided by advancements in the treatment of longitudinal data, the aim of

5 this study was to examine patterns and predictors of change in moderate-to-vigorous physical

6 activity (MVPA) and psychological distress (e.g., feeling nervous, worthless). Design: .

7 Method: Australian adults (4944 females, $M_{\text {age }}=34.63$ years $\pm 5.34 ; 4322$ males, $M_{\text {age }}=$

837.51 years \pm 6.14 ) provided baseline data as part of the Longitudinal Study of Australian

9 Children (LSAC) and were followed for measurements every two years for 10 years. Results:

10 Latent change score analyses revealed support for a reciprocal effects model, whereby change

11 in MVPA and psychological distress occurred as a function of individuals' prior levels of,

12 and/or prior change in these variables. Conclusions: This investigation is the first to

13 document that changes in MVPA and psychological distress are coupled temporally. Notably,

14 we observed that individuals' distress levels at a given time point predicted subsequent

15 change on both MVPA and distress; a finding which provides novel and important insight

16 into how adults' activity levels and psychological distress fluctuate relative to one another. 


\section{Longitudinal Relations Between Psychological Distress and Moderate-to-Vigorous}

\section{Physical Activity: A Latent Change Score Approach}

Psychological distress - symptoms of anxiety, depression, and other indices of distress that affect one's functional abilities - is prevalent in developed countries (e.g., Pratt, 2009) and has long been recognized as a key component of ill-being (see Veit \& Ware, 1983; Slade et al., 2011; Russ et al., 2012). The World Health Organization (WHO) estimates that there are up to 350 million cases of depression worldwide, and that depression will represent the leading cause of the global burden of disease by 2030 (WHO, 2012). It is well established that frequent moderate-to-vigorous physical activity (MVPA) is beneficial for one's overall health, and contributes to improved physical and psychosocial well-being (e.g., Del PozoCruz et al., 2018; García-Hermoso, Saavedra, Ramírez-Vélez, Ekelund, \& del Pozo-Cruz, 2017; Wiese, Kuykendall, \& Tay, 2017). The presence of well-being, however, does not necessarily indicate the absence of ill-being (Ryff et al., 2006), and accordingly, it is important to understand how activity (and inactivity) align with maladaptive health indices.

There remain unanswered questions regarding the precise nature of the relations between MVPA and indicators of ill-being (e.g., Mammen \& Faulkner, 2013). Drawing from a longitudinal study of Australian adults, the aim of this investigation was to examine trajectories of change in MVPA and psychological distress over a 10-year timeframe, and to model the way in which change in these variables may be coupled (i.e., inter-related).

Throughout, we consider psychological distress as a non-clinical state-like concept, rather than a chronic condition, where our focus is on assessing the frequency (rather than intensity) of distress. This conceptualization and operationalization is underpinned by a substantial body of work in which psychological distress is defined as a state of maladaptive psychological functioning characterized largely by emotional disturbances (Kessler et al., 2002). 
Our knowledge of the link between MVPA and (non-clinical) psychological distress has, to date, been driven primarily by investigations of the protective effect that MVPA may have upon psychological distress. An inverse relationship between MVPA and psychological distress has been observed in studies with adults (e.g., Brunes, Augestad, \& Gudmundsdottir, 2013; Cairney et al., 2009; De Mello et al., 2013; Perales et al., 2014), older adults (e.g., Ku, Fox, Chen \& Chou, 2012; Rosqvist et al., 2009), and adolescents (Birkeland, Torsheim, \& Wold, 2009; Motl, Birnbaum, Kubik, \& Disman, 2004). In terms of the dose-response relationship between MVPA and psychological distress, researchers have generally found that higher doses of MVPA among adults are associated with lower psychological distress (Hamer, Stamatakis, \& Steptoe, 2009; Sloan et al., 2013). There are many mechanisms that may explain the MVPA-psychological distress relationship. For instance, it is theorized that MVPA facilitates adaptive neurobiological (e.g., synthesis and release of neurotransmitters), physiological (e.g., fitness), social (e.g., interpersonal relationships), and psychological (e.g., self-esteem, mood) outcomes, which may in turn collectively buffer against psychological distress (see Salmon, 2001; Cairney et al., 2009; Matta Mello Portugal et al., 2013; Perales et al., 2014).

Just as MVPA may alleviate or prevent symptoms of depression and anxiety, psychological distress may deter participation in physical activity. Several mechanisms have been posited to explain the psychological distress-MVPA association (see Azevedo Da Silva et al., 2012). Symptoms of depression and anxiety are linked with increased risk of weight gain, which subsequently could negatively influence physical activity participation. Furthermore, individuals with depression and anxiety symptoms often experience feelings of social isolation and lower levels of energy or apathy, and therefore may be less motivated to participate in physical activities. Another possibility is that individuals with symptoms of depression may experience anhedonia (Leventhal, 2012), which is the inability to experience 
pleasure in response to rewarding stimuli. Thus, it is possible that individuals with anhedonia may find physical activity less pleasurable, which could in turn diminish one's desire or intent to engage in physical activity. It is also believed that psychological distress might be particularly disruptive for engaging in more intense (i.e., moderate and vigorous) forms of activity considering the effort that MVPA activities require and the characteristics (e.g., pattern of fatigue, diminished energy, and low motivation) of those who are psychologically distressed (Allan et al., 2007; Olive, Telford, Byrne, Abhayaratna, \& Telford, 2016). The precise mechanism(s), however, underlying the association between psychological distress and MVPA are unclear and remain to be examined.

There is some existing empirical research demonstrating that the association between MVPA and non-clinical psychological distress may be bi-directional (Azevedo Da Silva et al., 2012). Similar findings have also been reported in samples with older adults (e.g., Lindwall, Larsman, \& Hagger, 2011) and adolescents (e.g., Gunnell et al., 2016; Jerstad, Boutelle, Ness, \& Stice, 2010). However, much of the existing work in this area has relied on designs that do not allow researchers to capture change over time in these variables, despite MVPA and psychological distress being dynamic (i.e., changeable) in nature. As a result, insight into intra-individual change in MVPA and psychological distress (and the drivers of change) is limited. To the best of our knowledge, Gunnell et al.'s (2016) study is the only longitudinal investigation to examine bi-directionality and change in physical activity and symptoms of anxiety and depression using a community-based sample.

Using longitudinal data (five repeated measurements over a 10-year period) from a large cohort of Australian adults, our overarching aim was to explore changes in, and temporal coupling between, MVPA and psychological distress. In doing so, we sought to apply an increasingly-used method for modeling longitudinal data that places substantive importance on the concept of 'change', namely latent change score (LCS) analysis (see 
McArdle, 2009; McArdle \& Grimm, 2010, and for applied examples, Eschleman \& LaHuis,

2014; Li et al., 2014). LCS (or latent difference score) analysis enables researchers to

examine change over time and allows change to be modeled alongside 'raw' (e.g., time 1,

time 2, etc.) scores as a predictor or outcome in the analysis (e.g., to examine whether alongside MVPA/psychological distress scores at a given time point, prior change in MVPA/psychological distress predicts subsequent change in MVPA and psychological distress). Accordingly, the specific aim of this study was to examine the degree to which prior levels of MVPA and psychological distress, and changes in MVPA and psychological distress, predict subsequent changes in MVPA and psychological distress. Researchers have yet to (in a single study) examine changes over time in adults' MVPA and psychological distress, or to identify how these variables may act as dynamic determinants of one another (i.e., how change in each variable may predict subsequent change in each variable). Therefore, this study represents the first attempt to (a) model latent change in MVPA and psychological distress, and (b) estimate coupling effects and salient predictors of change on each variable. For that reason, although we anticipated inverse

110 relations between concepts (e.g., increases on MVPA associated with decreases on 111 psychological distress), our approach was exploratory insofar as we did not have sufficient

112 grounds to formulate specific a priori hypotheses regarding the relative strength of the 113 predictors of latent change between discrete time intervals.

\section{Methods}

\section{Sample}

116 The data for this study were taken from waves 1-5 of the K-cohort of the Longitudinal

117 Study of Australian Children (LSAC), where parents or guardians of children reported their 118 own physical activity behavior and psychological distress over a 10-year period. Full details 119 regarding LSAC sampling, recruitment, and data collection processes are detailed elsewhere 
120 (Nicholson \& Sanson, 2003; Sanson et al., 2002; Soloff, Lawrence, \& Johnstone, 2005).

121 Parents at wave 1 included 4944 females $(M=34.63$ years \pm 5.34$)$ and 4322 males $(M=$

12237.51 years \pm 6.14$)$. Overall, study retention across the five measurement points for

123 participants was relatively high (wave $2=90 \%$, wave $3=87 \%$, wave $4=84 \%$, and wave $5=$

$12479 \%$ ). In terms of highest level of education for females, $24.8 \%$ had completed a certificate,

$12516.1 \%$ achieved a Bachelor's degree, or obtained an advanced diploma (8.9\%), graduate

126 diploma (6.3\%), or postgraduate degree (5.9\%). With regard to the highest level of education

127 for males, $30.6 \%$ had completed a certificate, $13 \%$ achieved a Bachelor's degree, or obtained

128 an advanced diploma (7\%), postgraduate degree (6.8\%), or graduate diploma $(5.2 \%)$. The

129 LSAC was approved by the Australian Institute of Family Studies Ethics Committee; ethical

130 approval to access the LSAC dataset for the purposes of the current analyses was provided by

131 a Human Research Ethics Committee of the lead author's institution.

\section{Measures}

MVPA. A single item was employed to measure MVPA: "About how many days each week do you do at least 30 minutes of moderate or vigorous physical activity (for example, walking briskly, riding a bike, gardening, tennis, swimming, running, etc).” This question was asked of parents in a section in which participants reflected on their own health and feelings about life in general. Participants entered a numerical value of 0 - 7 in a blank form to indicate the number of days ${ }^{1}$. This measure is similar to single-item measures of MVPA that have been employed in past work (e.g., van Bree et al., 2017).

$140 \quad$ Psychological distress. Parents indicated the degree to which they felt six indicators of nonspecific psychological distress over the past four weeks (i.e., nervous, hopeless, restless or fidgety, so depressed that nothing could cheer you up, everything was an effort,

\footnotetext{
${ }^{1}$ Two participants recorded a response of 8 for this variable; given that the true maximum for this variable should be 7, we recoded these two values as missing for the purposes of the analyses in this study.
} 
143 worthless) using the Kessler Psychological Distress Scale (K6; Kessler et al., 2002).

144 Responses were recorded using a 5-point scale with the following anchors: 1 (all of the time),

1452 (most of the time), 3 (some of the time), 4 (a little of the time), and 5 (none of the time). To

146 aid interpretation, items were reversed scored then averaged to create a composite score for

147 psychological distress, such that higher scores reflected greater psychological distress. A

148 composite score of more than two on the K6 scale would indicate prevalence of serious

149 mental illness (Kessler et al. 2003). Reliability and validity evidence from test scores

150 obtained with large community samples support the utility of the K6 as a short measure of

151 psychological distress (e.g., Batterham, Sunderland, Slade, Calear, \& Carragher, 2018;

152 Kessler et al., 2010).

153 Covariates. In addition to age and sex, we considered family socioeconomic status

154 (SES) as a potential confounder in the main analyses. In the LSAC, family SES represents a composite of parent reports of equivalized annual family income, calculated by dividing total

156 income by total weightings for the family (each member has a different weighting), years of

157 education, and current or most recent occupational status. This variable is coded as a

158 standardized summary with a mean of 0 and standard deviation of 1 (Blackmore et al., 2006).

159 Data Analyses

160 Latent change scores (LCS; also referred to as latent difference scores) were

161 computed within a structural equation modeling framework to examine the temporal

162 dynamics between MVPA and psychological distress. Combining the strengths of latent

163 growth curve and cross-lagged structural models, LCS permits inferences regarding dynamic

164 forms of growth within specific temporal segments as well as multivariate relations (e.g.,

165 antecedents, moderators). Given our focus on the temporal coupling of MVPA and

166 psychological distress, LCS is the preferred approach because it permits an understanding of

167 which variables lead (i.e., change in construct A leads to change in construct B) and lag (i.e., 
development of construct B is coupled with yet lags behind construct A) in longitudinal associations (Grimm, Mazza, \& Mazzocco, 2016). As depicted in Figure 1, change in a variable is considered a function of (i) one's individual linear trajectory over time that encompasses the additive sum of changes (i.e., slope) and (ii) a quantity that is proportional to the lagged effect of the previous status or level of itself $(\beta)$. When the model includes two or more variables, the change score in one variable can be predicted by the previous level or status (coupling effect) or change in an alternative variable (change-to-change effect); these effects are depicted in Figures 2a-2d. Constraints are placed on various parameters to model the true latent change between two assessments, and test a range of different substantive questions (e.g., equality constraints to ascertain if the same dynamics are at play across all assessments). Interested readers are referred elsewhere for a comprehensive overview of the underlying statistical properties of LCS models (McArdle \& Hamagami, 2001), a userfriendly description of their utility for modeling changes in psychological research (Ferrer \& McArdle, 2010), and treatment of the differences between various types of analytical frameworks for analyzing change (Stenling, Ivarsson, \& Lindwall, 2016). Given our interest in lag-leading and reciprocal effects over time, we estimated four models in a sequential framework ${ }^{2}$. First, we estimated a baseline model for comparison with subsequent representations whereby MVPA and psychological distress were unable to predict changes in each other. To explore the utility of MVPA and psychological distress as a leading indicator of change, we then estimated two separate models that excluded reciprocal effects whereby one variable (e.g., MVPA) was allowed to predict subsequent change in the other

\footnotetext{
${ }^{2}$ The rationale to use measurement wave rather than chronological age as the time metric was statistically informed rather than substantive in nature. Specifically, the covariance coverage was problematic (i.e., <.18) when using chronological age as the time metric, particularly for participants aged 19-27 years and 49-70 years at the commencement of the study. This finding is unsurprising given that approximately $90 \%$ of participants were aged between 27 and 45 years, and therefore missing data for the age groups at the extremes of the age continuum was substantial (e.g., see Figures S1-S5 of the supplementary material for visual depictions). As such, the results of the analyses with age as the time metric cannot be trusted.
} 
variable (e.g., psychological distress). Finally, we modeled reciprocal effects of MVPA and psychological distress on each other such that each variable was permitted to affect upcoming change in the other construct. Proportional change effects were constrained to be the same across time in all four models. Visual displays of these models are provided in Figures $2 \mathrm{a}-2 \mathrm{~d}$. Model-data fit at each stage of the analysis was assessed using multiple indices and typical interpretation guidelines, namely the $\chi^{2}$ goodness-of-fit index, comparative fit index (CFI), Tucker-Lewis index (TLI), and root mean square error of approximation (RMSEA), with evidence of adequate fit indicated by CFI/TLI $\geq .90$ and RMSEA $\leq .08$ (Marsh et al., 2005). We performed all analyses with Mplus 7.4 (Muthén \& Muthén, 1998-2015) using a robust maximum likelihood estimator (MLR) and full information maximum likelihood (FIML). Missing data we handled using FIML with the assumption that the data were missing at random. FIML makes full use of all available data and is the preferred choice for handling missing data (Graham, 2009) because it provides minimally biased parameter estimates (Enders \& Bandalos, 2001). To account for the non-independence in the data (i.e., mother/father dyads), we used the TYPE = COMPLEX function in Mplus to appropriately adjust parameter estimates, standard errors, and the $\chi^{2}$ statistic (Muthén \& Muthén, 19982015). Given the sensitivity of the $\chi^{2}$ difference test with large samples (Meade et al., 2008), we prioritized the Akaike Information Criterion (AIC), the Bayesian Information Criterion (BIC), and its sample size adjusted version (ABIC) in the comparison of competing models, where smaller values indicate a better fitting model (Vrieze, 2012). We also performed robust chi-square difference tests to compare nested models (Bryant \& Satorra, 2012; Satorra \& Bentler, 2001).

\section{Results}

\section{Preliminary Analyses}


We excluded parent informants who did not have any data on the study variables across all five waves $(n=1082)$ or at least one full wave of completed responses $(n=108)$.

215 The means, standard deviations, and indices of univariate normality for MVPA and

216 psychological distress at each assessment point using FIML provide a descriptive overview of

217 the overall change in these variables (see Table 1). Mean psychological distress decreased

218 somewhat over the 10-year period (8.59\%), whereas mean MVPA increased slightly

219 (10.71\%). Bivariate correlations among the individual item scores are provided in the online supplementary material.

\section{Model Comparisons and Parameter Estimates}

All four models exhibited excellent model-data fit (see Table 2), though the reciprocal effects model was the best fitting model with the data as it had the lowest AIC, BIC and ABIC values. The likelihood ratio test also support the superiority of the reciprocal effects model (see Table 2). There were improvements in MVPA days per week between waves 1 and $3(\Delta 1=.32, \mathrm{SE}=.03 ; \Delta 2=.04, \mathrm{SE}=.03)$, yet these gains diminished in the latter two waves where decrements were observed $(\Delta 3=-.03, \mathrm{SE}=.02 ; \Delta 4=-.06, \mathrm{SE}=.02)$. Latent change scores indicated that there were decrements in psychological distress across most assessment periods $(\Delta 1=-.11, \mathrm{SE}=.01 ; \Delta 3=-.03, \mathrm{SE}=.01 ; \Delta 4=-.03, \mathrm{SE}=.01)$, with the exception of a small increase in psychological distress was observed between waves 2 and 3 $(\Delta 2=.04, \mathrm{SE}=.01)$. The standard errors indicated that the degree of interindividual variability in change scores was large for MVPA days per week, but small for psychological distress.

An overview of the unstandardized parameter estimates of the reciprocal effects model is presented in Table 3. To facilitate interpretation of the effects, we describe briefly the key findings regarding different parameters of the model. The slope means, which express constant linear changes for each individual, indicate that MVPA days per week decreased 
over time, whereas psychological distress increased throughout the 10-year period; these

239 findings are in contrast to the aggregate scores depicted in Table 1. It is important to note that

240 these estimates are made once all effects in the model are controlled, such as the effects of

241 change in MVPA days per week, psychological distress, and demographic factors on the

242 intercept and slope of constant change. There was salient variability in the slopes of both

243 MVPA days per week and psychological distress, thereby indicating individual differences in

244 the natural growth or change in these variables. With regard to the correlations between the

245 slope and intercepts factors, the results revealed that psychological distress changed more

246 rapidly in people who started with higher levels of psychological distress thereby indicative

247 of a ceiling effect. The correlation between intercepts revealed that people with higher levels

248 of psychological distress reported lower levels of exercise at the start of the collection period;

249 equally, individuals with higher levels of exercise at the first data collection point reported

250 lower levels of psychological distress.

Findings indicated that there was a positive linear change component for

psychological distress. That change component was proportional to prior status on

psychological distress and MVPA days per week, such that higher levels of psychological distress and MVPA days per week at the previous measurement wave were associated with lower increases in distress at subsequent waves. The MVPA days per week findings shared both similarities with, and differences from, psychological distress. Changes in psychological

257 distress predicted future MVPA days per week changes, such that upward changes in

258 psychological distress downregulated future MVPA. Although changes in psychological

259 distress predicted changes in MVPA days per week, the reverse was untrue. Change in 
the previous measurement wave, the greater the increase in MVPA days per week at the subsequent wave.

\section{Discussion}

It has been demonstrated that regular participation in MVPA is linked with lower psychological distress (e.g., Perales et al., 2014). It has been suggested that psychological

267 distress may, in turn, limit MVPA involvement (e.g., Olive et al., 2016); however, there is limited longitudinal evidence to verify this assertion. Despite our knowledge of the potential reciprocal relationships between these concepts, limited attention has been directed toward understanding how these variables change relative to one another over time. Using data collected as part of a 10-year, multi-wave longitudinal study, we modeled latent change in these variables with the goal of providing insight into patterns and predictors of change in MVPA days per week and psychological distress. MVPA days per week and psychological distress occurred as a function of prior levels of, and prior change in, each variable. In terms of noteworthy overarching findings, negatively correlated intercepts revealed that - at the outset of the collection period - higher psychological distress was associated with lower MVPA days per week (and vice versa), lending support to previous similar findings (e.g., Hamer et al., 2009). In terms of understanding intra-individual change over the 10-year study period, results showed that the constant linear change component of MVPA days per week decreased over time, whereas

282 psychological distress increased. In addition, the slopes for MVPA days per week and psychological distress were negatively correlated, indicating that linear growth in one variable (e.g., increased MVPA) was broadly associated with reductions in the other variable (e.g., decreased psychological distress). Supporting evidence for the relations between growth patterns of MVPA and psychological distress is limited; however, the correlated slopes that 
we observed align with the reductions in psychological distress that have been observed in physical activity promotion trials (e.g., Li et al, 2001; Bilderbeck et al., 2013).

Analyses also revealed that change over time in psychological distress was catalyzed by one's prior level of both psychological distress and MVPA days per week, such that higher previous levels of MVPA and psychological distress predicted smaller increases in psychological distress at subsequent waves. In other words, higher MVPA days per week at a given time appeared to buffer against increases in psychological distress in the future (i.e., a protective role of MVPA), and higher levels of psychological distress at a given time resulted in a reduced possibility for that distress to increase in the next wave (i.e., a ceiling effect).

Regarding the predictors of change in MVPA days per week, one's prior level of, and change in, psychological distress (but not MVPA) were substantively important. Specifically, higher previous levels of psychological distress were associated with larger decreases in MVPA days per week at the subsequent wave, and previous upward change on psychological distress promoted subsequent downward change on MVPA. Collectively, these findings support the role of frequent MVPA in dampening increases in psychological distress; however, psychological distress level was the most salient predictor of change in this study. In particular, individuals' distress levels predicted subsequent change on both variables of interest. Future work designed to replicate this finding for psychological distress and MVPA is encouraged.

The strengths of this study include the use of a large, broadly population representative sample, the longitudinal nature of the data, and the implementation of a latent change modeling strategy. Also, these findings are important in a practical sense; strategies designed to monitor and alleviate (or at least, prevent increases in) individuals' psychological distress, for example, may prove fruitful for encouraging positive subsequent change in MVPA. Moreover, efforts to stimulate higher levels of MVPA over time (e.g., interventions 
312 that are designed to stimulate manageable and persistent increases in MVPA) may in turn

313 protect against increases in psychological distress.

314 Balanced against these strengths, it is important to acknowledge design limitations

315 and to highlight associated future research directions. First, although the reliance on self-

316 report MVPA assessment methods is understandable given the scope of data collection, this

317 approach is accompanied by limitations relating to inaccurate reporting, a lack of sensitivity,

318 and social desirability concerns. It would be worthwhile in future to supplement self-report

319 assessments with objective MVPA tracking, and capture more detailed information about

320 participants' activity patterns (e.g., modality, intensity, duration). In addition, it is recognized

321 that psychological factors - such as one's body image, depression, and anxiety - may

322 contribute to biased estimates of behavior and health status (e.g., Maurer et al., 2006; Gil \&

323 Mora, 2011). It is possible, therefore, that the psychological distress (i.e., depression, anxiety

324 symptoms) experienced by participants may have resulted in some inaccuracy in MVPA

325 estimation, which may explain, at least in part, why MVPA levels/change predicted

326 psychological distress but not MVPA.

327 A more sensitive and frequent assessment protocol than every two years may also be

328 valuable for the measurement of psychological distress. As well as being subject to

329 recollection biases, the scheduling of this assessment may have resulted in a failure to capture

330 important variation in distress, and more frequent assessment schedules (e.g., using

331 experience sampling, diary-based methods) would be worthwhile in future work. Finally,

332 despite controlling for important demographic factors (i.e., sex, age, SES) in this study,

333 researchers are encouraged to assess other life events (e.g., childbirth, bereavements) and

334 related factors (e.g., social support) that may predict patterns of change in, and relations

335 between, MVPA and psychological distress. To conclude, by modeling latent change over a

336 10-year period, this study advances our knowledge of the dynamic interplay between 
337 trajectories of MVPA and psychological distress, and offers methodological and analytical 338 innovation for future work aimed at exploring dynamic coupling between physical activity 339 and other physical and mental health indices. 


\section{References}

Allan, J.L., Johnston, D.W., Johnston, M., \& Mant, D., (2007). Depression and perceived behavioral control are independent predictors of future activity and fitness after coronary syndrome events. Journal of Psychosomatic Research, 63, 501-508.

Azevedo Da Silva, M. A., Singh-Manoux, A., Brunner, E. J., Kaffashian, S., Shipley, M. J., Kivimäki, M., \& Nabi, H. (2012). Bidirectional association between physical activity and symptoms of anxiety and depression: The Whitehall II study. European Journal of Epidemiology, 27, 537-546.

Batterham, P.J., Sunderland, M., Slade, T., Calear, A.L., \& Carragher, N. (2018). Assessing distress in the community: Psychometric properties and crosswalk comparison of eight measures of psychological distress. Psychological Medicine 48, 1316-1324.

Bilderbeck, A.C., Farias, M., Brazil, I.A., Jakobowitz, S., \& Wikholm, C. (2013).

Participation in a 10-week course of yoga improves behavioural control and decreases psychological distress in a prison population. Journal of Psychiatric Research, 47, $1438-1445$.

Birkeland, M. S., Torsheim, T., \& Wold, B. (2009). A longitudinal study of the relationship between leisure-time physical activity and depressed mood among adolescents. Psychology of Sport and Exercise, 10, 25-34.

Blackmore, T., Gibbings, J., \& Strazdins, L. (2006). Measuring the socio-economic position of families in HILDA \& LSAC. ACSPRI Social Science Methodology Conference, University of Sydney. (https://old.acspri.org.au/conference2006/proceedings/streams/SEP\%20paper.\%2013_1 1_06.pdf). Accessed 14 August 2016. 
Brunes, A., Augestad, L.B., \& Gudmundsdottir, S.L. (2012). Personality, physical activity, and symptoms of anxiety and depression: The HUNT study. Social Psychiatry and Psychiatric Epidemiology, 48, 745-756.

Bryant, F. B., \& Satorra, A. (2010). Principles and practice of scaled difference chi-square testing. Structural Equation Modeling, 19, 372-398.

Cairney, J., Faulkner, G., Veldhuizen, S., \& Wade, T.J. (2009). Changes over time in physical activity and psychological distress among older adults. The Canadian Journal of Psychiatry, 54, 160-169.

Del Pozo-Cruz, J., García-Hermoso, A., Alfonso-Rosa, R.M., Alvarez-Barbosa, F., Owen, N., Chastin, S., \& del Pozo-Cruz, B. (2018). Replacing sedentary time: Meta-analysis of objective-assessment studies. American Journal of Preventative Medicine, 55, 395402.

De Mello, M.T., Lemos, V., Antunes, H.K.M., Bittencourt, L., Santos-Silva, R., \& Tufik, S. (2013). Relationship between physical activity and depression and anxiety symptoms: A population study. Journal of Affective Disorders, 149, 241-246.

Enders, C. K., \& Bandalos, D. L. (2001). The relative performance of full information maximum likelihood estimation for missing data in structural equation models. Structural Equation Modeling, 8, 430-457.

Eschleman, K.J., \& LaHuis, D. (2014). Advancing occupational stress and health research and interventions using latent difference score modeling. International Journal of Stress Management, 21, 112.

Ferrer, E., \& McArdle, J.J. (2010). Longitudinal modeling of developmental changes in psychological research. Current Directions in Psychological Science, 19, 149-154.

García-Hermoso, A., Saavedra, J.M., Ramírez-Vélez, R., Ekelund, U. \& del Pozo-Cruz, B. (2017). Reallocating sedentary time to moderate-to-vigorous physical activity but not to 
light-intensity physical activity is effective to reduce adiposity among youths: A systematic review and meta-analysis. Obesity Reviews, 18, 1088-1095.

Gil, J., \& Mora, T. (2011). The determinants of misreporting weight and height: The role of social norms. Economics \& Human Biology, 9, 78-91.

Graham, J. W. (2009). Missing data analysis: making it work in the real world. Annual Review of Psychology, 60, 549-576.

Grimm, K. L., Mazza, G. L., \& Mazzocco, M. M. M. (2016). Advances in methods for assessing longitudinal change. Educational Psychologist, 51, 342-353. doi: $10.1080 / 00461520.2016 .1208569$

Gunnell, K. E., Flament, M.F., Buchholz, A., Henderson, K. A., Obeid, N., Schubert, N., \& Goldfield, G. S. (2016). Examining the bidirectional relationship between physical activity, screen time, and symptoms of anxiety and depression over time during adolescence. Preventive Medicine, 88, 147-152.

Hamer, M., Stamatakis, E., \& Steptoe, A. (2009). Dose-response relationship between physical activity and mental health: The Scottish Health Survey. British Journal of Sports Medicine, 43, 1111-1114.

Jerstad, S.J., Boutelle, K.N., Ness, K.K., Stice, E. (2010). Prospective reciprocal relations between physical activity and depression in female adolescents. Journal of Consulting and Clinical Psychology, 78, 268-272.

Kessler, R.C., Andrews, G., Colpe, L.J., Hiripi, E., Mroczek, D.K., Normand, S.L., et al. (2002). Short screening scales to monitor population prevalences and trends in nonspecific psychological distress. Psychological Medicine, 32, 959-976.

Kessler, R.C., Barker, P.R., Colpe, L.J., Epstein, J.F., Gfroerer, J.C., Hiripi, E., et al. (2003). Screening for serious mental illness in the general population. Archives of General Psychiatry, 60, 184-189. 
Kessler, R.C., Green, J.G., Gruber, M.J., Sampson, N.A., Bromet, E., Cuitan, M., ... Zaslavsky, A.M. (2010). Screening for serious mental illness in the general population with the K6 screening scale: Results from the WHO World Mental Health (WMH) survey initiative. International Journal of Methods Psychiatric Research, 19(S1), 4- 22.

Ku, P.W., Fox, K.R., Chen, L.J., \& Chou, P. (2012). Physical activity and depressive symptoms in older adults: 11-year follow-up. American Journal of Preventive Medicine, 42, 355-362.

Leventhal, A. (2012). Relations between anhedonia and physical activity. American Journal of Health Behavior, 36, 860-872.

Li, F., Duncan, T.E., Duncan, S.C., McAuley, E., Chaumeton, N.R., \& Harmer, P. (2001). Enhancing the psychological well-being of elderly individuals through Tai Chi exercise: A latent growth curve analysis. Structural Equation Modeling, 8, 53-83.

Li, W.D., Fay, D., Frese, M., Harms, P.D., \& Gao, X.Y. (2014). Reciprocal relationship between proactive personality and work characteristics: A latent change score approach. Journal of Applied Psychology, 99, 948.

Lindwall, M., Larsman, P., \& Hagger, M. S. (2011). The reciprocal relationship between physical activity and depression in older European adults: A prospective cross-lagged panel design using SHARE data. Health Psychology, 30, 453-462.

Mammen, G., \& Faulkner, G. (2013). Physical activity and the prevention of depression: A systematic review of prospective studies. American Journal of Preventive Medicine, 45, 649-657.

Matta Mello Portugal, E., Cevada, T., Sobral Monteiro-Junior, R., Teixeira Guimarães, T., da Cruz Rubini, E., Lattari, E., Blois, C., \& Camaz Deslandes, A. (2013). Neuroscience of exercise: From neurobiology mechanisms to mental health. Neuropsychobiology, 68, 114. doi:10.1159/000350946 
Marsh, H.W., Hau, K-T, \& Grayson, D. (2005). Goodness of fit evaluation in structural equation modeling. In A. Maydeu-Olivares \& J. McArdle (Eds.), Psychometrics. A Festschrift for Roderick P. McDonald (pp. 275-340). Erlbaum: Hillsdale, NJ.

Maurer, J., Taren, D.L., Teixeira, P.J., Thomson, C.A., Lohman, T.G., Going, S.B., et al. (2006). The psychosocial and behavioral characteristics related to energy misreporting. Nutrition Reviews, 64, 53-66.

McArdle, J.J. (2009). Latent variable modeling of differences and changes with longitudinal data. Annual Review of Psychology, 60, 577-605.

McArdle, J.J., \& Grimm, K.J. (2010). Five steps in latent curve and latent change score modeling with longitudinal data. In K. von Montfort, J.H.L. Oud \& A. Satorra (Eds.), Longitudinal Research with Latent Variables (pp. 245-273). Springer: Berlin Heidelberg.

McArdle, J.J., \& Hamagami, F. (2001). Linear dynamic analyses of incomplete longitudinal data. In L. Collins \& A. Sayer (Eds.), New Methods for the Analysis of Change (pp. 137-176). APA Press: Washington, DC.

Meade, A.W., Johnson, E.C., \& Braddy, P.W. (2008). Power and sensitivity of alternative fit indices in tests of measurement invariance. Journal of Applied Psychology, 93, 568592.

Motl, R.W., Birnbaum, A.S., Kubik, M.Y., Dishman, R.K. (2004). Naturally occurring changes in physical activity are inversely related to depressive symptoms during early adolescence. Psychosomatic Medicine, 66, 336-342.

Mouchacca, J., Abbott, G.R., \& Ball, K. (2013). Associations between psychological stress, eating, physical activity, sedentary behaviours and body weight among women: A longitudinal study. BMC Public Health, 13, 828. 
Muthén, L.K., \& Muthén, B.O. (1998-2015). Mplus user's guide (7th ed.). Los Angeles, CA: Muthén \& Muthén.

Nicholson, J.M., \& Sanson, A. (2003). A new longitudinal study on the health and well-being of Australian children: How will it help? Medical Journal of Australia, 178, 282-284.

Olive, L.S., Telford, R.M., Byrne, D.G., Abhayaratna, W.P., \& Telford, R.D. (2016). Psychological distress leads to reduced physical activity and fitness in children: The Australian longitudinal LOOK study. Journal of Behavioral Medicine, 39, 587-598.

Perales, F., Pozo-Cruz, J.D., \& Pozo-Cruz, B.D. (2014). Impact of physical activity on psychological distress: A prospective analysis of an Australian national sample. American Journal of Public Health, 104, e91-e97.

Pratt, L.A. (2009). Serious psychological distress, as measured by the K6, and mortality. Annals of Epidemiology, 19, 202-209.

Rosqvist, E., Heikkinen, E., Lyyra, T.M., Hirvensalo, M., Kallinen, M., Leinonen, R., ...Rantanen, T. (2009). Factors affecting the increased risk of physical inactivity among older people with depressive symptoms. Scandinavian Journal of Medicine \& Science in Sports, 19, 398-405.

Russ, T.C., Stamatakis, E., Hamer, M., Starr, J.M., Kivimäki, M., \& Batty, G.D. (2012). Association between psychological distress and mortality: Individual participant pooled analysis of 10 prospective cohort studies. BMJ 345:e4933.

Ryff, C.D., Love, G.D., Urry, H.L., Muller, D., Rosenkranz, M.A., Friedman, E.M., et al. (2006). Psychological well-being and ill-being: Do they have distinct or mirrored biological correlates? Psychotherapy and Psychosomatics, 75, 85-95.

Salmon, P. (2001). Effects of physical exercise on anxiety, depression, and sensitivity to stress: A unifying theory. Clinical Psychology Review, 21, 33-61. 
Sanson, A., Nicholson, J., Ungerer, J., Zubrick, S., Wilson, K., Ainley, J., et al. (2002). Introducing the Longitudinal Study of Australian Children. LSAC discussion paper no. 1.

(http://www.growingupinaustralia.gov.au/pubs/discussion/dp1/discussionpaper1.pdf). Accessed 14 August 2016.

Satorra, A., \& Bentler, P. M. (2001). A scaled difference chi-square test statistic for moment structure analysis. Psychometrika, 66, 507-514.

Slade, T., Grove, R., \& Burgess, P. (2011). Kessler psychological distress scale: normative data from the 2007 Australian National Survey of Mental Health and Wellbeing. Australian and New Zealand Journal of Psychiatry, 45, 308-316.

Sloan, R.A., Sawada, S.S., Girdano, D., Liu, Y.T., Biddle, S.J., \& Blair, S.N. (2013). Associations of sedentary behavior and physical activity with psychological distress: A cross-sectional study from Singapore. BMC Public Health, 13, 885.

Soloff, C., Lawrence, D., \& Johnstone, R. (2005). Sample design, LSAC Technical Paper no. 1. Melbourne, Australia: Australian Institute of Family Studies. Retrieved from http://www.growingupinaustralia.gov.au/pubs/technical/tp1.pdf.

Stenling, A., Ivarsson, A., \& Lindwall, M. (2016). The only constant is change: Analyzing and understanding change in sport and exercise psychology research. International Review of Sport and Exercise Psychology, 10, 230-251.

van Bree, R. J. J., Bolman, C., Mudde, A. N., van Stralen, M. M., Peels, D. A., de Vries, H., \& Lechner, L. (2017). Modelling longitudinal relationships between habit and physical activity: Two cross-lagged panel design studies in older adults. Journal of Aging and Physical Activity, 25, 464-473.

Veit, C.T., \& Ware, J.E (1983). The structure of psychological distress and well-being in general populations. Journal of Consulting and Clinical Psychology, 51, 730-742. 
Vrieze, S.I. (2012). Model selection and psychological theory: A discussion of the differences between the Akaike information criterion (AIC) and the Bayesian information criterion (BIC). Psychological Methods, 17, 228- 243.

Wiese, C., Kuykendall, L., \& Tay, L. (2017). Get active? A meta-analysis of leisure-time physical activity and subjective well-being. Journal of Positive Psychology, 13, 57-66.

World Health Organization (2012). Depression: A global crisis.

(http://www.who.int/mental_health/management/depression/wfmh_paper_depression_ wmhd_2012.pdf). Accessed 15 February 2017. 


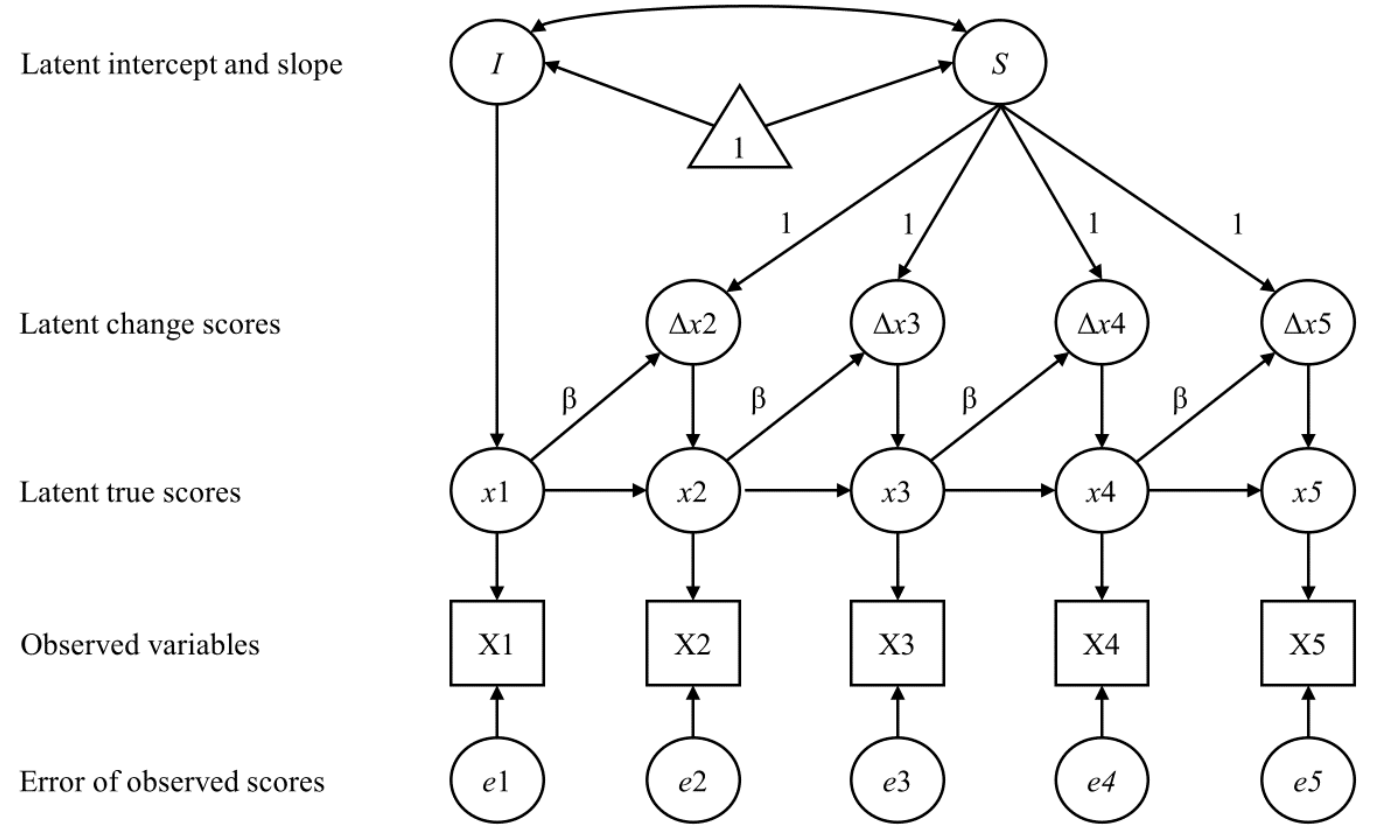

Figure 1. Univariate latent change score model. 
$\underline{\text { Year of Assessment }}$
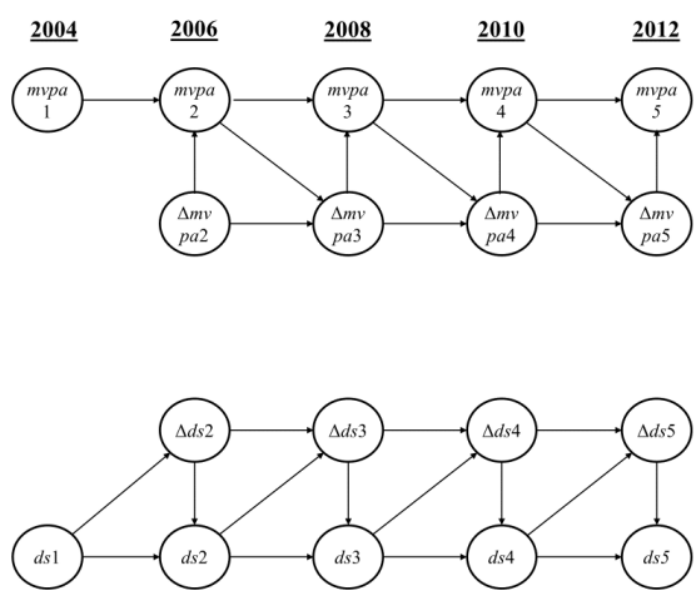

Model 1

Year of Assessment

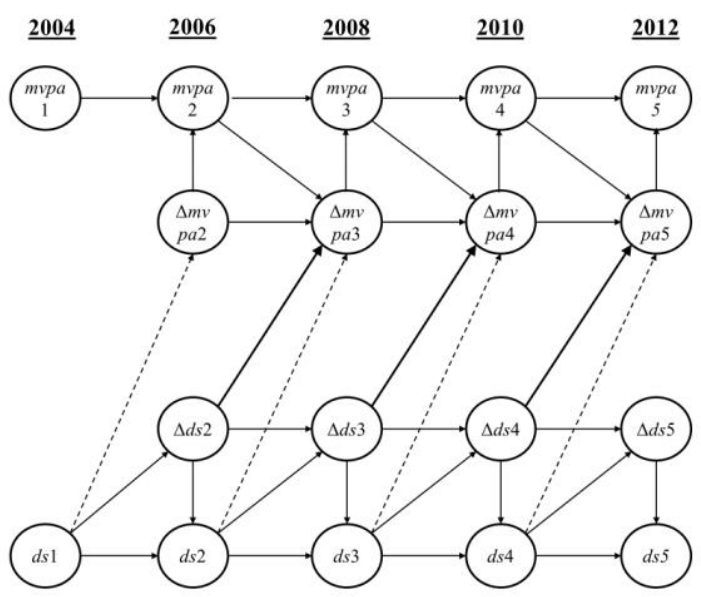

$\underline{\text { Year of Assessment }}$

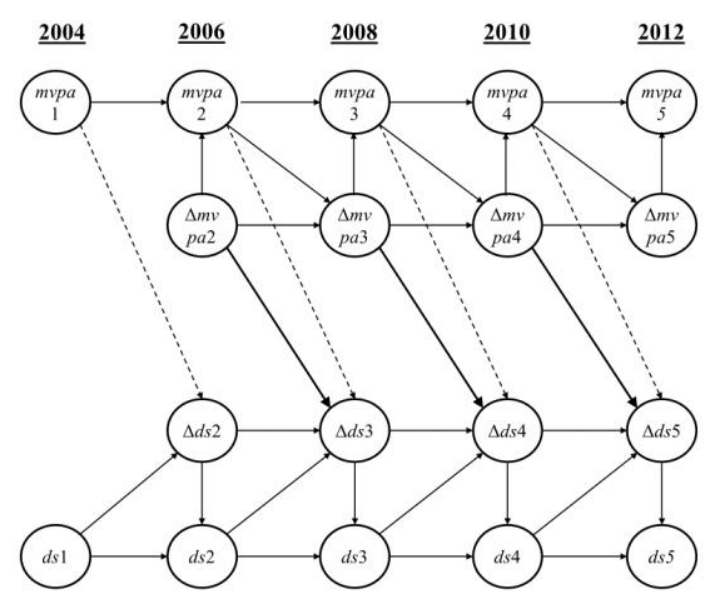

Model 2

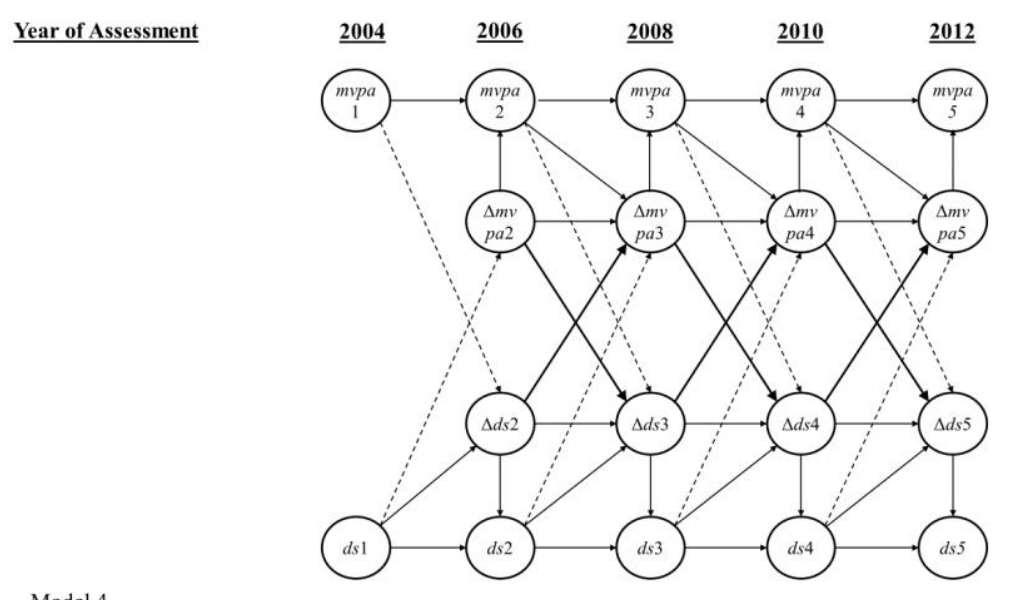

Model 4

Model 3

Figure 2. Visual representations of latent change score models tested. Note: model 1 = baseline; model 2 = effects of MVPA on distress only; model 3 = effects of distress on MVPA only; model 4 = reciprocal effects of MVPA and distress. For clarity of presentation, latent slope and intercept factors, observed variables, residual variances are excluded. 
Table 1. Descriptive statistics for study variables at each measurement wave using fullinformation maximum likelihood estimation.

\begin{tabular}{lllllll}
\hline & $\mathrm{N}$ & Mean & SD & Skewness & Kurtosis & Range \\
\hline MVPA at wave 1 & 7479 & 2.80 & 2.01 & .48 & -.61 & $0-7$ \\
MVPA at wave 2 & 6183 & 3.11 & 2.00 & .34 & -.73 & $0-7$ \\
MVPA at wave 3 & 6198 & 3.14 & 1.97 & .32 & -.75 & $0-7$ \\
MVPA at wave 4 & 6601 & 3.08 & 2.00 & .31 & -.78 & $0-7$ \\
MVPA at wave 5 & 6005 & 3.10 & 2.02 & .25 & -.83 & $0-7$ \\
Distress at wave 1 & 7424 & 1.63 & .60 & 1.52 & 3.05 & $1-5$ \\
Distress at wave 2 & 7138 & 1.53 & .57 & 1.90 & 4.96 & $1-5$ \\
Distress at wave 3 & 6320 & 1.56 & .58 & 1.72 & 3.77 & $1-5$ \\
Distress at wave 4 & 6607 & 1.51 & .57 & 1.96 & 5.02 & $1-5$ \\
Distress at wave 5 & 6207 & 1.49 & .58 & 2.08 & 5.74 & $1-5$ \\
Age & 8564 & 36.04 & 5.81 & .46 & 1.28 & $19-70$ \\
Socioeconomic & 8564 & .10 & .97 & .28 & -.40 & $-3.73-3.00$ \\
status & & & & & & \\
\hline
\end{tabular}

\footnotetext{
${ }^{1}$ Socioeconomic status was standardized.
} 
Table 2. Model-data fit indices and likelihood ratio tests for latent change score models for frequency of weekly sessions of moderate-tovigorous physical activity and psychological distress.

\begin{tabular}{lllll}
\hline & Baseline (1) & MVPA $\rightarrow$ Distress (2) & Distress $\rightarrow$ MVPA (3) & Reciprocal (4) \\
\hline$\chi^{2}(\mathrm{df})$ & $465.55(65)$ & $404.62(63)$ & $426.13(63)$ & $344.49(61)$ \\
$p$ & $<.001$ & $<.001$ & $<.001$ & $<.001$ \\
RMSEA (90\% CI) & $.027(.025$ to .029$)$ & $.025(.023$ to .028$)$ & $.026(.024$ to .028$)$ & $.024(.021$ to .026$)$ \\
CFI & .972 & .976 & .975 & .980 \\
TLI & .968 & .972 & .970 & .976 \\
AIC & 177149.76 & 177057.50 & 177091.70 & 177000.55 \\
BIC & 177361.42 & 177283.27 & 177317.47 & 177240.44 \\
ABIC & 177266.08 & 177181.58 & 177215.79 & 177132.39 \\
\hline Model 1 vs 2 & $39.25(2), p<.001$ & & & \\
Model 1 vs 3 & $30.86(2), p<.001$ & & & \\
Model 2 vs 4 & $4.86(2), p=.044$ & & & \\
Model 3 vs 4 & $570.43, p<.001$ & & & \\
\hline
\end{tabular}

Note: ${ }^{\#}=$ model comparison performed using a robust chi-square difference test (Satorra \& Bentler, 2001); ${ }^{*}=$ the robust chi-square difference test can sometimes produce a negative value; we utilized an alternative approach (Bryant \& Satorra, 2012) to circumvent this issue for the comparison of model 2 with 4. 
Table 3. Unstandardized parameter estimates of reciprocal latent difference score model.

\begin{tabular}{|c|c|c|c|c|}
\hline & B & SE & $p$ & $95 \% \mathrm{CI}$ \\
\hline MVPA slope $(\mu)$ & -8.15 & 2.61 & .002 & $-13.26,-3.05$ \\
\hline MVPA intercept $(\mu)$ & 3.65 & .19 & $<.001$ & $3.29,4.02$ \\
\hline Distress slope $(\mu)$ & 3.54 & .58 & $<.001$ & $2.41,4.68$ \\
\hline Distress intercept $(\mu)$ & 1.48 & .05 & $<.001$ & $1.37,1.58$ \\
\hline MVPA slope $\left(\sigma^{2}\right)$ & 4.34 & 2.11 & .04 & $.20,8.47$ \\
\hline MVPA intercept $\left(\sigma^{2}\right)$ & 2.07 & .06 & $<.001$ & $1.95,2.18$ \\
\hline Distress slope $\left(\sigma^{2}\right)$ & .68 & .20 & .001 & $.28,1.07$ \\
\hline Distress intercept $\left(\sigma^{2}\right)$ & .20 & .01 & $<.001$ & $.18, .21$ \\
\hline \multicolumn{5}{|l|}{ Correlations } \\
\hline Distress slope $\leftrightarrow$ distress intercept & .34 & .05 & $<.001$ & $.24, .44$ \\
\hline Distress slope $\leftrightarrow$ MVPA slope & -1.69 & .66 & .01 & $-2.99,-.39$ \\
\hline Distress slope $\leftrightarrow$ MVPA intercept & .20 & .09 & .02 & $.03, .37$ \\
\hline Distress intercept $\leftrightarrow$ MVPA slope & -.87 & .20 & $<.001$ & $-1.28,-.49$ \\
\hline Distress intercept $\leftrightarrow$ MVPA intercept & -.10 & .01 & $<.001$ & $-.12,-.07$ \\
\hline & -.19 & .39 & .63 & $-.95, .58$ \\
\hline & \multicolumn{4}{|c|}{ Proportional Effects } \\
\hline & & .25 & .34 & \\
\hline \multicolumn{5}{|l|}{ Coupling Effects } \\
\hline MVPA status $\rightarrow$ distress change & -.18 & .05 & .001 & $-.28,-.07$ \\
\hline $\begin{array}{l}\text { Distress status } \rightarrow \text { MVPA change } \\
\text { Change to Change Effects }\end{array}$ & 4.84 & 1.18 & $<.001$ & $2.53,7.15$ \\
\hline MVPA change $\rightarrow$ distress change & -.03 & .05 & .51 & $-.13, .06$ \\
\hline $\begin{array}{c}\text { Distress change } \rightarrow \text { MVPA change } \\
\text { Covariates }\end{array}$ & -1.72 & .55 & .001 & $-2.79,-.66$ \\
\hline Sex $\rightarrow$ distress slope & .11 & .03 & $<.001$ & $.05, .16$ \\
\hline Age $\rightarrow$ distress slope & -.005 & .002 & .03 & $-.01, .00$ \\
\hline $\mathrm{SES} \rightarrow$ distress slope & -.12 & .02 & $<.001$ & $-.16,-.08$ \\
\hline Sex $\rightarrow$ distress intercept & .12 & .01 & $<.001$ & $.09, .14$ \\
\hline Age $\rightarrow$ distress intercept & .00 & .001 & .74 & $-.003, .002$ \\
\hline $\mathrm{SES} \rightarrow$ distress intercept & -.06 & .01 & $<.001$ & $-.08,-.05$ \\
\hline Sex $\rightarrow$ MVPA slope & -.36 & .07 & $<.001$ & $-.52,-.22$ \\
\hline Age $\rightarrow$ MVPA slope & .01 & .01 & .07 & $-.001, .02$ \\
\hline SES $\rightarrow$ MVPA slope & .33 & .09 & $<.001$ & $.17, .53$ \\
\hline Sex $\rightarrow$ MVPA intercept & -.34 & .04 & $<.001$ & $-.42,-.24$ \\
\hline Age $\rightarrow$ MVPA intercept & -.01 & .004 & .04 & $-.02,-.001$ \\
\hline SES $\rightarrow$ MVPA intercept & -.11 & .03 & $<.001$ & $-.16,-.06$ \\
\hline
\end{tabular}

Note: $\mathrm{B}=$ unstandardized effect $; \mathrm{SE}=$ standard error $; \mu-$ mean; $\sigma^{2}=$ variance. 
MVPA and distress latent changes 30

Supplementary Material 


\section{Chronological Age as the Time Metric}

As noted the manuscript, the rationale to use measurement wave rather than chronological age as the time metric was statistically informed rather than substantive in nature. In Mplus, zero coverage is not an issue when data on a variable is totally missing because it would not be used as part of the estimation process (e.g., consider a hypothetical situation in which we include ages 16,17 , and 18 in the statistical model). However, low coverage is a problem when there are data points for a variable (Linda Muthén, personal communication; January $29^{\text {th }}, 2019$ ). Even using 3-year age ranges such as $19-21,22-24$, and so on, as the time metric (e.g., Finkel et al., 2007) cannot alleviate this covariance coverage problem in the current sample. Essentially, we would need to remove participants at these age extremes for the analyses to be trustworthy, something we opted not to do because it could be interpreted as "p hacking", etc. For example, there were only a handful of data points for the 3-year age groups of 67-69 $(n=10), 70-72(n=10)$, and 73-75 $(n=5)$, compared with 37-39 $(\mathrm{n}=4606), 40-42(\mathrm{n}=4734)$, and 43-45 $(\mathrm{n}=3727)$. Nevertheless, some readers may be interested in a comparison of the results obtained with chronological age as the time metric (using 3-year age ranges) with those obtained using measurement wave; full details of these results are provided in Tables $\mathrm{S} 1$ and $\mathrm{S} 2$ below. 


\section{References}

Finkel, D., Reynolds, C.A., McArdle, J.J., \& Pedersen, N.L. (2007). Age changes in processing speed as a leading indicator of cognitive change. Psychology and Aging, 22, 558-568. 
Table S1. Model-data fit indices and likelihood ratio tests for latent change score models with age as the time metric for frequency of weekly sessions of moderate-to-vigorous physical activity and psychological distress.

\begin{tabular}{lcccc}
\hline & Baseline (1) & MVPA $\rightarrow$ Distress (2) & Distress $\rightarrow$ MVPA (3) & Reciprocal (4) \\
\hline$\chi^{2}(\mathrm{df})$ & - & - & - & - \\
$p$ & - & - & - & - \\
RMSEA $(90 \% \mathrm{CI})$ & - & - & - & - \\
CFI & - & - & - & - \\
TLI & - & 134799.37 & 134808.07 & 134772.57 \\
AIC & 134809.19 & 134996.92 & 135005.62 & 134984.23 \\
BIC & 134992.63 & 134907.94 & 134916.64 & 13488.89 \\
ABIC & 134910.00 & & & - \\
\hline
\end{tabular}

Note: the robust chi-square could not be computed for all models due to low covariance coverage. 
Table S2. Unstandardized parameter estimates of reciprocal latent difference score model.

\begin{tabular}{|c|c|c|c|c|}
\hline & $\mathrm{B}$ & SE & $p$ & $95 \% \mathrm{CI}$ \\
\hline MVPA slope $(\mu)$ & 2.31 & 2.09 & .26 & $-1.78,6.40$ \\
\hline MVPA intercept $(\mu)$ & 4.15 & .38 & $<.001$ & $3.39,4.90$ \\
\hline Distress slope $(\mu)$ & .89 & .69 & .19 & $-.45,2.24$ \\
\hline Distress intercept $(\mu)$ & 1.55 & .45 & .001 & $.67,2.43$ \\
\hline MVPA slope $\left(\sigma^{2}\right)$ & .30 & .48 & .54 & $-.64,1.23$ \\
\hline MVPA intercept $\left(\sigma^{2}\right)$ & 3.70 & 1.91 & .052 & $-.04,7.44$ \\
\hline Distress slope $\left(\sigma^{2}\right)$ & .05 & .07 & .48 & $-.08, .18$ \\
\hline Distress intercept $\left(\sigma^{2}\right)$ & .57 & .28 & .043 & $.02,1.12$ \\
\hline \multicolumn{5}{|l|}{ Correlations } \\
\hline Distress slope $\leftrightarrow$ distress intercept & .10 & .06 & .12 & $-.03, .22$ \\
\hline Distress slope $\leftrightarrow$ MVPA slope & .10 & .06 & .08 & $-.01, .21$ \\
\hline Distress slope $\leftrightarrow$ MVPA intercept & -.01 & .14 & .94 & $-.29, .26$ \\
\hline Distress intercept $\leftrightarrow$ MVPA slope & .24 & .17 & .15 & $-.09, .57$ \\
\hline Distress intercept $\leftrightarrow$ MVPA intercept & -.03 & .37 & .94 & $-.75, .69$ \\
\hline MVPA slope $\leftrightarrow$ MVPA intercept & \multicolumn{2}{|c|}{ Proportional Effects } & .71 & $-1.47,2.16$ \\
\hline MVPA status $\rightarrow$ MVPA change & -.31 & 31 & 32 & -92.30 \\
\hline $\begin{array}{c}\text { Distress status } \rightarrow \text { distress change } \\
\text { Coupling Effects }\end{array}$ & -.52 & .21 & .015 & $-.93,-.10$ \\
\hline MVPA status $\rightarrow$ distress change & -.05 & .12 & .67 & $-.28, .18$ \\
\hline $\begin{array}{l}\text { Distress status } \rightarrow \text { MVPA change } \\
\text { Change to Change Effects }\end{array}$ & -.85 & .71 & .23 & $-2.24, .54$ \\
\hline MVPA change $\rightarrow$ distress change & -.51 & .43 & .23 & $-1.36, .33$ \\
\hline $\begin{array}{c}\text { Distress change } \rightarrow \text { MVPA change } \\
\text { Covariates }\end{array}$ & Covariates & .18 & .94 & $-.34, .37$ \\
\hline Sex $\rightarrow$ distress slope & .04 & .02 & .007 & $.01, .07$ \\
\hline $\mathrm{SES} \rightarrow$ distress slope & -.02 & .01 & .19 & $-.04, .01$ \\
\hline Sex $\rightarrow$ distress intercept & .18 & .12 & .11 & $-.04, .41$ \\
\hline SES $\rightarrow$ distress intercept & .04 & .03 & .23 & $-.02, .10$ \\
\hline Sex $\rightarrow$ MVPA slope & .01 & .04 & .75 & $-.07, .10$ \\
\hline SES $\rightarrow$ MVPA slope & -.04 & .07 & .62 & $-.18, .11$ \\
\hline Sex $\rightarrow$ MVPA intercept & -.55 & .21 & .008 & $-.95,-.14$ \\
\hline SES $\rightarrow$ MVPA intercept & -.21 & .37 & .57 & $-.93, .51$ \\
\hline
\end{tabular}

Note: $\mathrm{B}=$ unstandardized effect $; \mathrm{SE}=$ standard error $; \mu-$ mean; $\sigma^{2}=$ variance. 

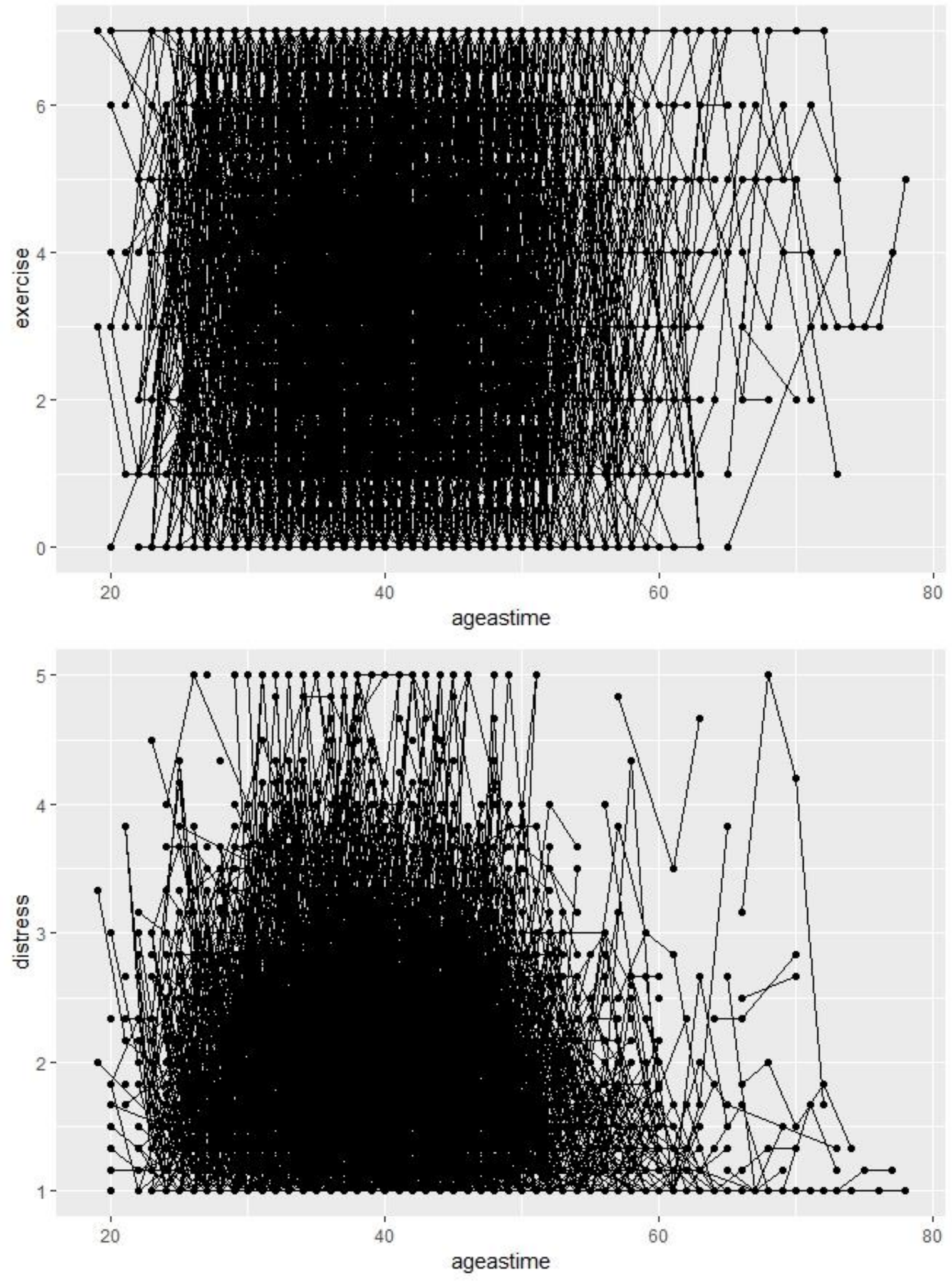

Figure S1. Spaghetti plots of MVPA (top) and psychological distress (bottom) over time by a function of chronological age of participants. 

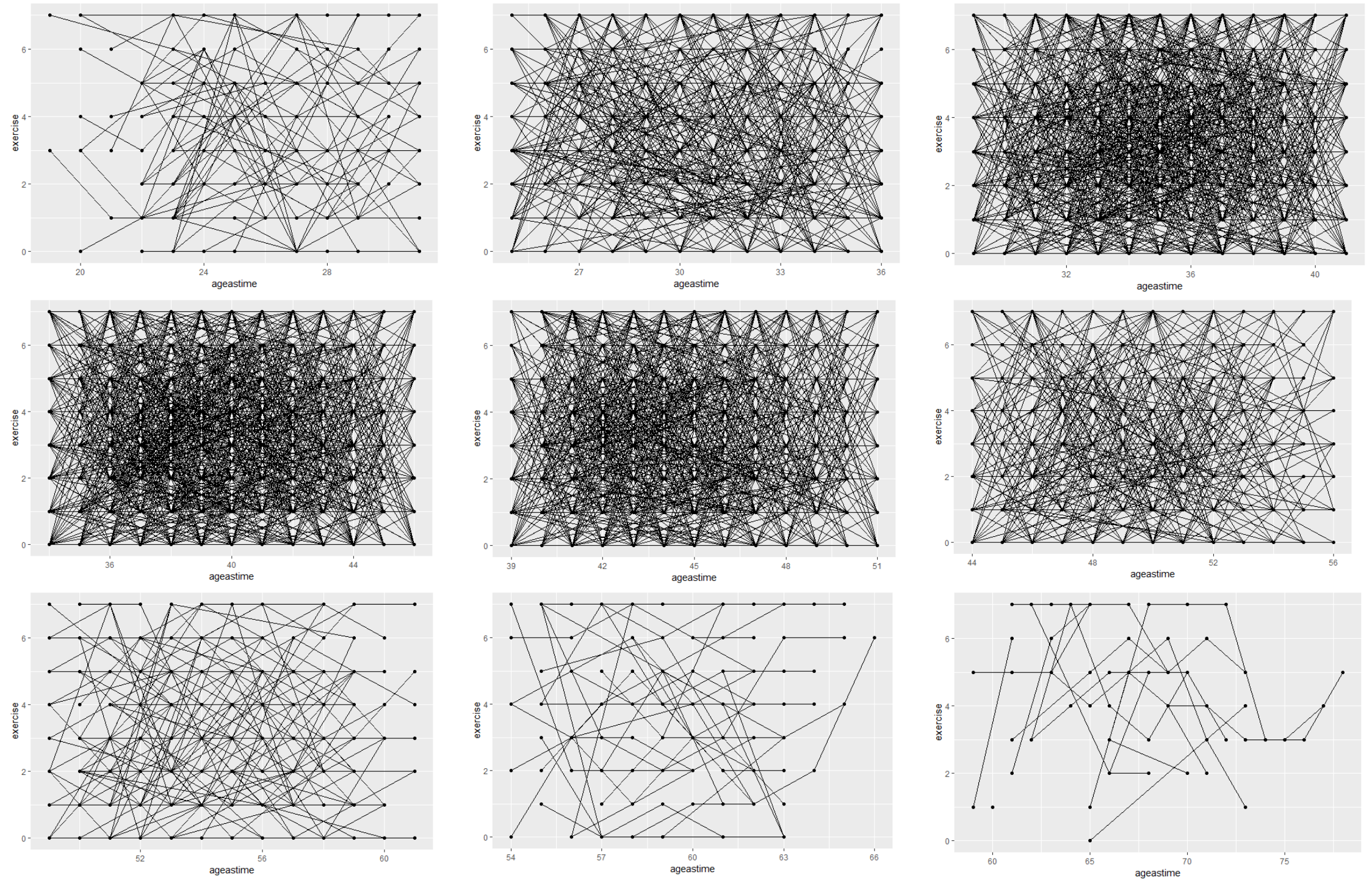

Figure S2. Spaghetti plots of MVPA over time by a function of chronological age of participants. 

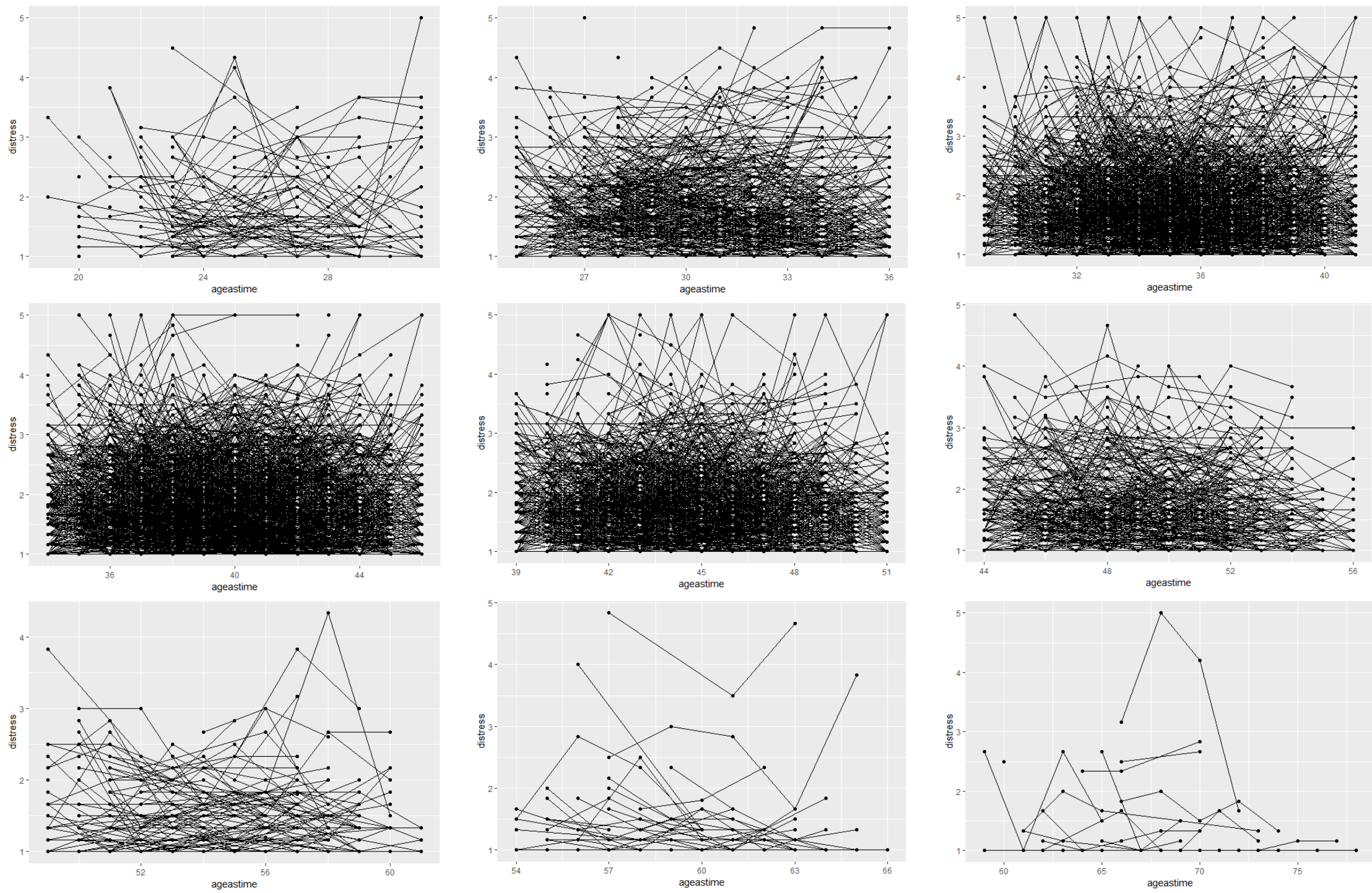

Figure S3. Spaghetti plots of psychological distress over time by a function of chronological age of participants. 


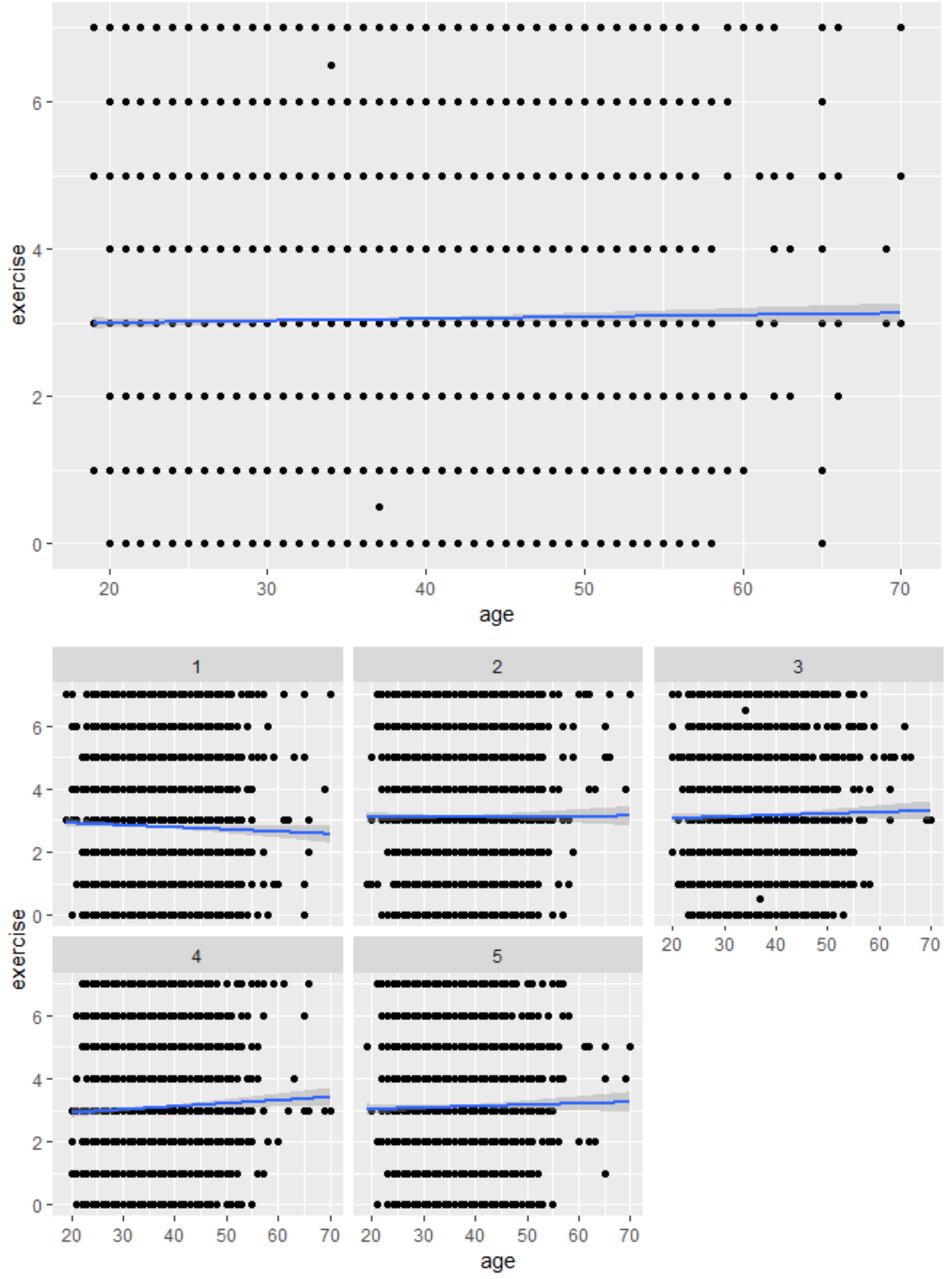

Figure S4. Bivariate correlation between age and MVPA among the total sample for all waves (top) and by each measurement wave (bottom). 

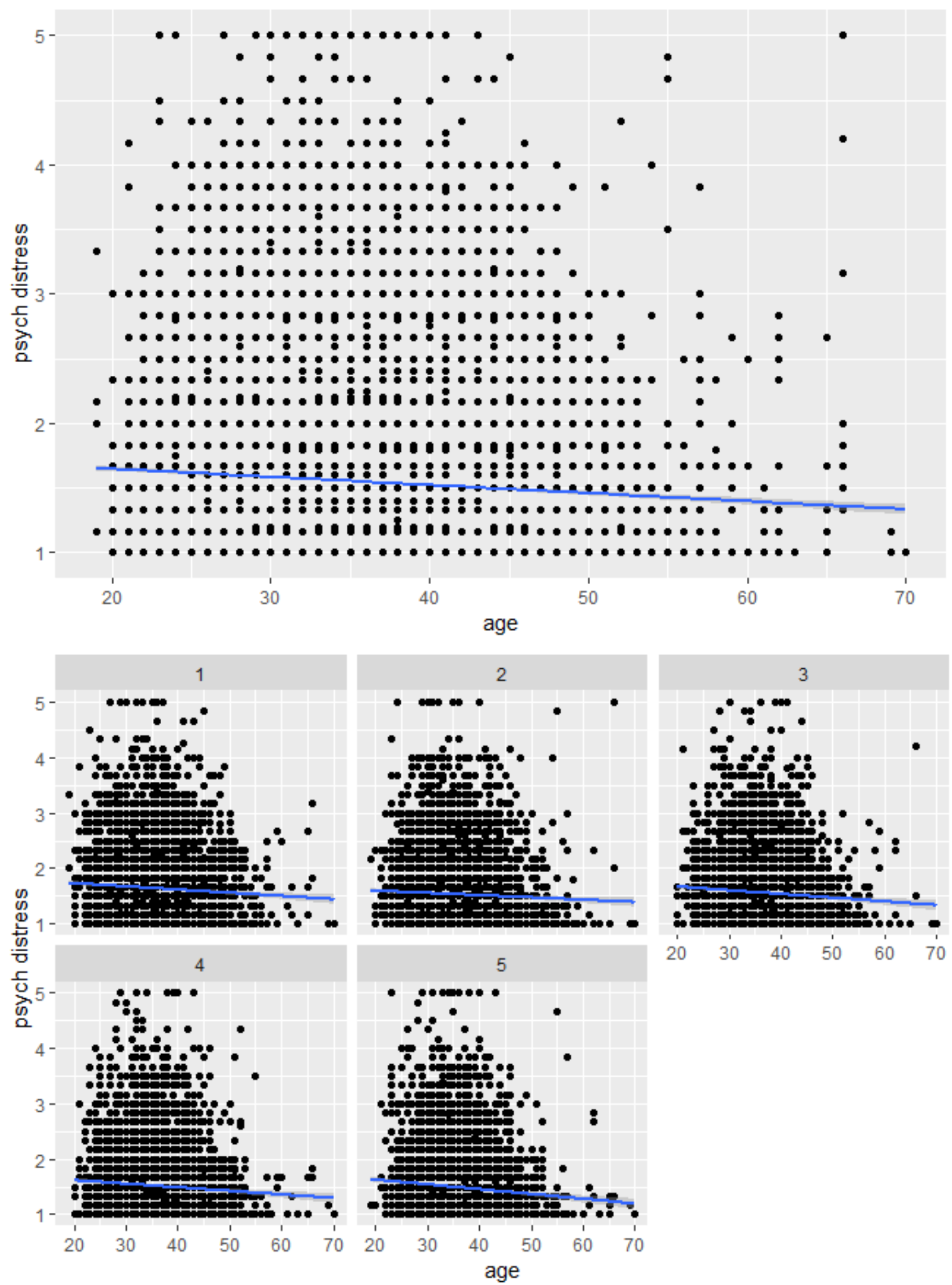

Figure S5. Bivariate correlation between age and psychological distress among the total sample for all waves (top) and by each measurement wave (bottom). 